\title{
Necrotizing infundibulo-hypophysitis: an entity too rare to be true?
}

\author{
Angelika Gutenberg • Patrizio Caturegli • \\ Imke Metz $\cdot$ Ramon Martinez $\cdot$ Alexander Mohr • \\ Wolfgang Brück $\cdot$ Veit Rohde
}

Published online: 10 April 2011

(c) The Author(s) 2011. This article is published with open access at Springerlink.com

\begin{abstract}
We report a young woman with sudden and severe retroorbital headache, neck pain, and a large sellar mass extending to the suprasellar cistern. A presumptive diagnosis of non-secreting pituitary macroadenoma undergoing apoplexy was made and transphenoidal surgery performed. Histopathology revealed mononuclear infiltration and marked non-hemorrhagic necrosis of the anterior pituitary consistent with a diagnosis of necrotizing infundibulohypophysitis. The possible pathogenesis of this rare variant of hypophysitis is discussed.
\end{abstract}

Keywords Hypophysitis $\cdot$ Necrosis $\cdot$ Pituitary infarction

\section{Introduction}

Necrosis results from several types of insults and presents with morphologically distinct patterns. In the anterior pituitary, necrosis is usually of vascular origin and more often associated with pituitary adenomas (Table 1). It is

\footnotetext{
A. Gutenberg $(\bowtie) \cdot$ R. Martinez $\cdot$ V. Rohde

Department of Neurosurgery, University Medical Center, Georg August University, 37099 Göttingen, Germany

e-mail: agutenberg@med.uni-goettingen.de

I. Metz $\cdot$ W. Brück

Department of Neuropathology, University Medical Center, Georg August University, Göttingen, Germany

A. Mohr

Department of Neuroradiology, University Medical Center, Georg August University, Göttingen, Germany

P. Caturegli

Department of Pathology and Immunology, The Johns Hopkins University School of Medicine, Baltimore, MD, USA
}

found at surgery or during pathological examination of the resected sellar mass [3], often accompanied by hemorrhages (hemorrhagic necrosis). In a minority of cases, it develops so rapidly and extensively that it causes a sudden increase in the size of the pituitary gland accompanied by symptoms such as headache, visual disturbances, ophthalmoplegia, nausea, vomiting, and altered mental status, an emergency condition known as pituitary apoplexy. Pituitary necrosis is also typical of Sheehan syndrome. It is an ischemic necrosis resulting from the hypotension that ensues after severe uterine bleeding at the time of delivery [4]. It typically results in gradual hypopituitarism that may remain unrecognized for years; however, a few patients may develop acute pituitary apoplexy.

In very rare cases, necrosis is observed in hypophysitis, a chronic inflammation of the pituitary gland that comprises two more common forms, lymphocytic and granulomatous, and two rarer forms, xanthomatous and $\mathrm{IgG} 4$ plasmacytic $[1,2]$. In these forms, necrosis is typically limited to small areas and does not dominate the histopathological picture [2]. In 1993, however, Ahmed and colleagues described 2 patients with a fifth pathological variant they called necrotizing infundibulo-hypophysitis [3]. They reported two young men with central diabetes insipidus, partial hypopituitarism, and MRI features suggestive of hypophysitis (enlarged anterior pituitary and thickened stalk) who underwent pituitary surgery. Analysis of the resected tissue showed extensive necrosis surrounded by a lympho-plasmacytic infiltration and fibrosis, with only scattered areas of glandular tissue remaining. A third case was reported in the Japanese literature in a 14 year-old boy with a prolonged history of diabetes insipidus, but the diagnosis of necrotizing infundibuloneurohypophysitis was established without pituitary biopsy, so its classification remains uncertain [4]. 
Table 1 Etiology of pituitary necrosis

\begin{tabular}{ll}
\hline Tumorous & Pituitary adenoma \\
& Pituitary metastases \\
Ischemic & Sheehan syndrome \\
Thrombotic/ & Antepartum necrosis of gestational diabetes \\
Hypercoagulative & Septic shock \\
Autoimmune & Hypophysitis \\
Mechanical & Elevated intracranial pressure (secondary to \\
& subarachnoidal hemorrhage, basilar artery \\
& thrombosis) \\
Miscellaneous & Pituitary stimulation test \\
& Spinal anesthesia \\
& Snake venom poisoning \\
\hline
\end{tabular}

We report here the third case of biopsy-proven necrotizing infundibulo-hypophysitis in a young woman who presented with severe headache and secondary amenorrhea and was carefully followed up for 1 year after pituitary surgery.

\section{Case report}

A 20 year-old woman with a three-year history of migraine and secondary amenorrhea suddenly developed severe retroorbital headache and neck pain. Physical examination and visual acuity were normal. Visual fields could not be assessed because headache rendered the ophthalmic perimetry intolerable, despite sufficient analgesic coverage.

Magnetic resonance imaging (MRI) revealed a $22 \times$ $20 \times 16 \mathrm{~mm}$ pituitary mass with slight suprasellar extension (Fig. 1). The pituitary mass was iso- to hyperintense on T2- (Fig. 1a) and hyperintense on T1-weighted images (Fig. 1b). The typical posterior pituitary bright spot was absent (Fig. 1d). After i.v. contrast (gadolinium), only slight to moderate and inhomogeneous enhancement occurred, most pronounced in the periphery of the mass (Fig. 1c). The pituitary stalk and infundibulum were slightly thickened and showed avid enhancement (Fig. 1e).

Assessment of pituitary function revealed increased prolactin and secondary hypogonadism (Table 2). Thyroid, adrenal, and growth hormone axes were normal. A

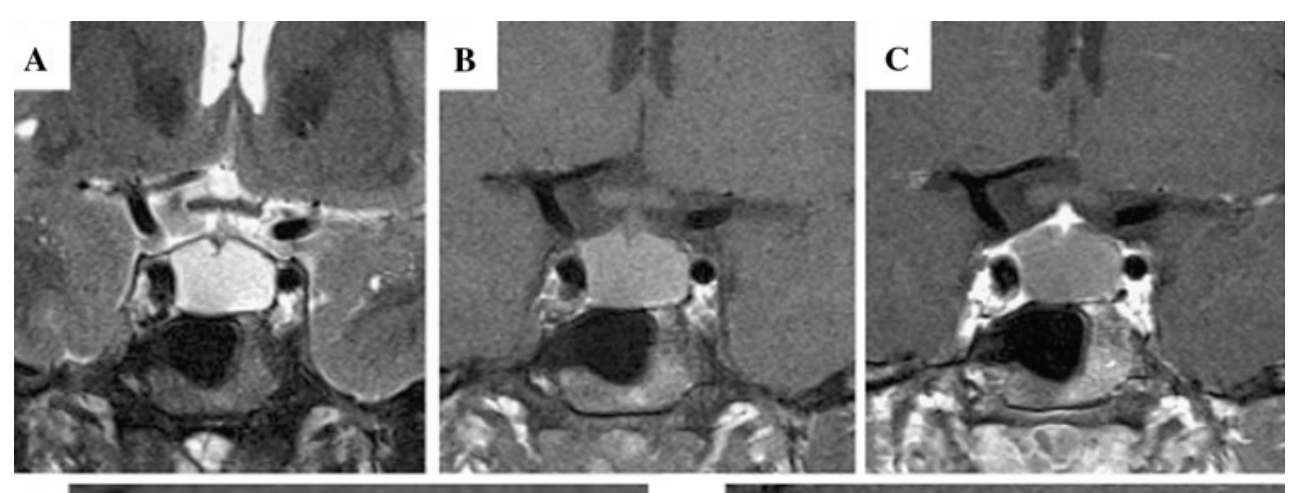

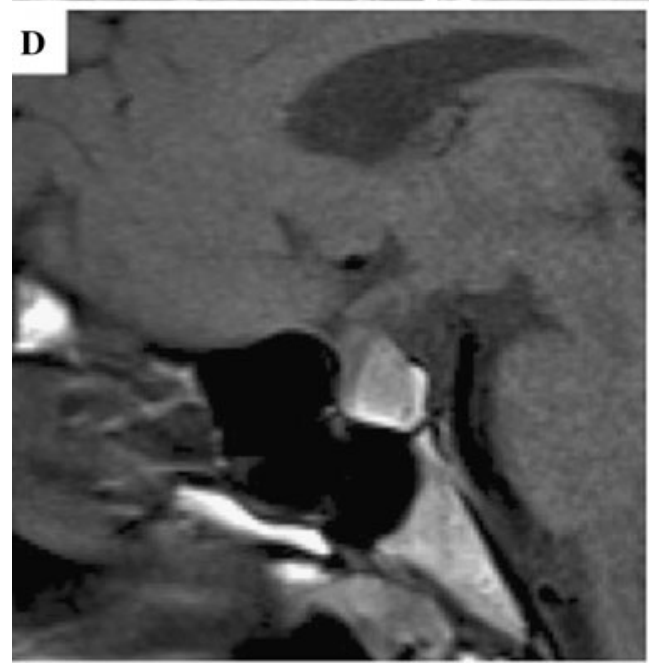

Fig. 1 Magnetic resonance imaging before surgery. The $22 \times$ $20 \times 16 \mathrm{~mm}$ pituitary mass is iso- to hyperintense on T2 with suprasellar extension (a) and hyperintense in T1-weighted, nonenhanced images. The typical posterior pituitary bright spot is absent

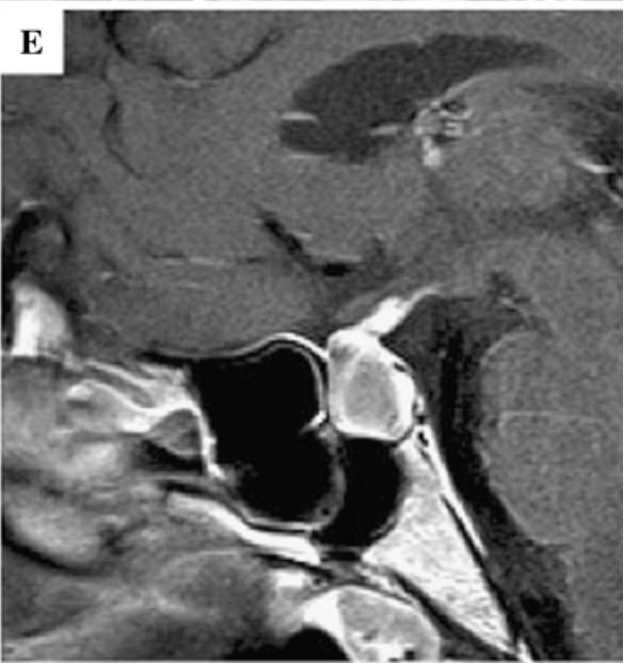

(d). After i.v. contrast (c), only slight to moderate and inhomogeneous enhancement occurs, most pronounced at the periphery of the mass. The pituitary stalk and infundibulum are slightly thickened showing avid enhancement $(\mathbf{d})$ 
Table 2 Endocrinological characteristics before and after pituitary surgery

\begin{tabular}{|c|c|c|c|c|c|}
\hline Hormone & Reference value & Method & $\begin{array}{l}2 \text { days } \\
\text { before surgery }\end{array}$ & $\begin{array}{l}3 \text { months } \\
\text { after surgery }\end{array}$ & $\begin{array}{l}6 \text { months } \\
\text { after surgery }\end{array}$ \\
\hline Prolactin & $91-552 \mathrm{mU} / \mathrm{l}$ & ECLIA & 628 & 1,955 & 108 \\
\hline LH & $0.8-8.3 \mathrm{mU} / \mathrm{ml}$ & ECLIA & 0.7 & 0.6 & $0.6^{\mathrm{a}}$ \\
\hline FSH & $1.2-10.1 \mathrm{mU} / \mathrm{ml}$ & ECLIA & 0.52 & 0.8 & $1.0^{\mathrm{a}}$ \\
\hline Estradiol & $30-330 \mathrm{pg} / \mathrm{ml}$ & ECLIA & $<7.0$ & $<7.0$ & $116.8^{\mathrm{a}}$ \\
\hline TSH & $0.45-3.20 \mathrm{mU} / \mathrm{l}$ & ECLIA & 0.87 & 3.81 & 0.50 \\
\hline fT3 & $2.4-4.4 \mathrm{ng} / \mathrm{l}$ & ECLIA & 2.9 & 2.9 & 2.5 \\
\hline fT4 & $8.9-17.0 \mathrm{ng} / \mathrm{l}$ & ECLIA & 12.7 & 9.5 & 7.4 \\
\hline ACTH & $7.2-63.3 \mu \mathrm{g} / 1$ & ECLIA & 10.3 & 6.9 & $<1.0^{\mathrm{b}}$ \\
\hline Cortisol (baseline) & $5-25 \mu \mathrm{g} / \mathrm{dl}$ & ECLIA & 72 & $84^{\mathrm{c}}$ & $415^{\mathrm{b}}$ \\
\hline Cortisol (30 min after $250 \mu \mathrm{g}$ ACTH) & $>30 \mu \mathrm{g} / \mathrm{dl}$ & ECLIA & $\mathrm{nm}$ & 112 & $\mathrm{~nm}$ \\
\hline Cortisol (60 min after $250 \mu \mathrm{g}$ ACTH) & $>70 \mu \mathrm{g} / \mathrm{dl}$ & ECLIA & $\mathrm{nm}$ & 137 & $\mathrm{~nm}$ \\
\hline GH & $<6.88 \mu \mathrm{g} / 1$ & CLA & 1.1 & $\mathrm{~nm}$ & $\mathrm{~nm}$ \\
\hline IGF-1 & $108-247 \mu \mathrm{g} / \mathrm{l}$ & CLA & $\mathrm{nm}$ & 156 & 98 \\
\hline
\end{tabular}

nm: not measured

ECLIA: electrochemiluminescencs assay (Roche Diagnostics, Mannheim, Germany)

CLIA: chemiluminescens immuno assay (DiaSorin, Dietzenbach, Germany)

Italics within this table are used for pathological values

${ }^{a}$ Under estradiol substitution

a,b Under hydrocortisone substitution

c Two days after discontinuing hydrocortisone

diagnosis of non-secreting macroadenoma with pituitary apoplexy was established based on clinical findings and imaging. The patient was started on hydrocortisone (40 mg/day) and prepared for surgery. A transseptal transsphenoidal surgical approach to the pituitary was performed 2 days after the onset of headaches.

Opening of the sella revealed no hemorrhage but rather a fleshy, gum-like mass intimately connected with a rubbery pituitary. The components of the gland that appeared pathological were completely removed. The remaining gland was inspected extensively and showed no other areas suggestive of tumor or hemorrhage.

Pathological evaluation of the excised tissue revealed no adenoma. The key feature was instead an abundance of necrotic tissue with only small areas of anterior and posterior pituitary remaining. These areas were heavily infiltrated by mononuclear cells (Fig. 3a, b), with abundant CD8-positive cytotoxic T cells in both anterior (Fig. 3c, d) and posterior pituitary (Fig. 3e, f). The remaining anterior pituitary showed acini of secretory cells surrounded by a reticulin-rich network. Single cells were positive when stained for the different hormones (ACTH, GH, TSH, FSH, LH, PRL). Small areas of the posterior pituitary showed regular pituicytes with partial expression of glial fibrillary acidic protein (GFAP).

After surgery the patient developed diabetes insipidus, which was treated with desmopressin replacement, as well as adynamia despite hydrocortisone therapy. At the 3 month follow-up, the headaches had ceased, the initial hormonal defects (hyperprolactinemia and secondary hypogonadism) persisted (Table 2), the diabetes insipidus was controlled by desmopressin (spray every $16 \mathrm{~h}$ ), and a secondary adrenal insufficiency was detected by an ACTH stimulation test (serum cortisol measured after intravenous $250 \mu \mathrm{g}$ of ACTH) (Table 2). Six months after surgery, normoprolactinemia was seen under estradiol substitution, but decreased free thyroxine $(7.4 \mathrm{ng} / \mathrm{l})$ and inappropriately normal TSH values $(0.5 \mathrm{mU} / \mathrm{l})$ indicated the appearance of secondary hypothyroidism, and decreased IGF-1 levels $(98 \mu \mathrm{g} / \mathrm{l})$ a concomitant growth hormone deficiency. Adynamia improved after initiation of thyroxine replacement $(50 \mu \mathrm{g} /$ day) and continuation of hydrocortisone (then $20 \mathrm{mg} / \mathrm{day}$ ). Overall this progression to panhypopituitarism suggested that, despite surgical removal of the inflamed and necrotic pituitary mass, the remaining pituitary parenchyma was still targeted by the autoimmune attack. Up to the present, the patient has not been affected by other autoimmune diseases.

Control cranial MRI were performed 6 and 9 months after surgery. At 6 months, the anterior pituitary and the stalk appeared normal in size (Fig. 2a), but there was still no normal T1 hyperintense signal in the posterior pituitary (Fig. 2c). A $4 \times 7 \times 6 \mathrm{~mm}$ sized cyst was also found in the left sellar region. After administration of gadolinium (Fig. 2b), the remaining anterior pituitary and stalk were 

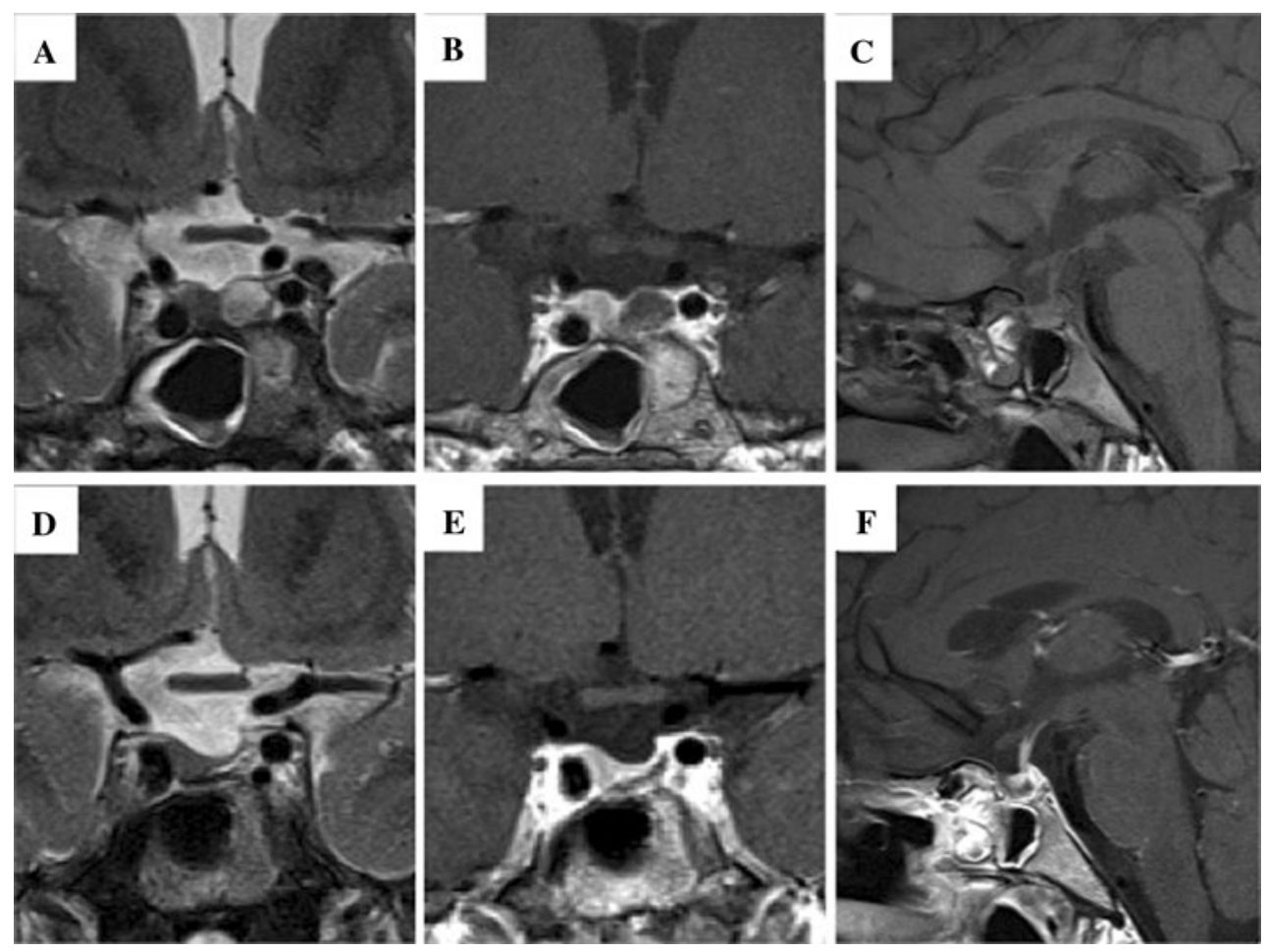

Fig. 2 Magnetic resonance imaging at 6 and 9 months after surgery. Six months after surgery, MRI revealed a left intrasellar cyst of $4 \times 7 \times 6 \mathrm{~mm}$ (a) with normal-appearing anterior pituitary and pituitary stalk, not enhancing after gadolinium (b). There is still no normal T1 hyperintense signal of the posterior pituitary (c). Nine

physiologically enhanced but no enhancement of the intrasellar cyst was observed. At 9 months, the anterior pituitary and stalk maintained their normal size and enhanced normally (Fig. 2d-f). The physiologic posterior pituitary bright spot in non-enhanced T1 images was still lacking (data not shown), and the left intrasellar cyst had disappeared.

\section{Discussion}

We describe a case of hypophysitis with inflammatory infiltration of the anterior and posterior pituitary and partial necrosis of the anterior pituitary, consistent with the diagnosis of necrotizing infundibulo-hypophysitis. This condition is extremely rare; only 3 cases have been previously reported, diagnosed in two patients [3], and suspected in a third [4]. The diagnosis of necrotizing infundibulo-hypophysitis is based solely on pathological examination of the resected pituitary since the clinical presentation and the MRI appearance do not differ from other more common forms of hypophysitis. The more common forms of hypophysitis are lymphocytic, granulomatous and xanthomatous [1]. Patients with necrotizing infundibulo-hypophysitis present acutely with sudden and months after surgery MRI demonstrates a normal anterior pituitary and pituitary stalk with normal enhancement $(\mathbf{d}-\mathbf{f})$, but the normal posterior pituitary bright spot in non-enhanced $\mathrm{T} 1$ images is still lacking (not shown)

severe headache and develop a complete and long-lasting hypopituitarism, features that can, however, be seen in other non-secreting pituitary masses [5]. MRI reveals symmetrical enlargement of the pituitary gland without signs of hemorrhage, as well as a thickened, pathologically enhancing stalk, features that again are not specific enough to establish a diagnosis before pituitary surgery. Confirmation of the diagnosis of necrotizing infundibulohypophysitis, as in other forms of hypophysitis, requires the pathological examination of the surgically removed pituitary specimen.

The key diagnostic feature of necrotizing infundibulohypophysitis is a marked mononuclear infiltrate within pituitary tissue showing significant necrosis. Pituitary necrosis can be found in various conditions (Table 1), most commonly in adenomas with apoplexy [6, 7] and Sheehan syndrome $[8,9]$. Pituitary necrosis is also seen in gestational diabetes mellitus [10], hypophysitis, and sporadically after pituitary stimulation tests [11], spinal anesthesia [12], or snake poisoning [13]. In routine autopsy series, pituitary necrosis is found in about $10 \%$ of cases without neoplasms [14]. In the majority of published series on pituitary apoplexy, no differentiation is made between pure infarction or infarction with hemorrhage, and very few cases of pituitary apoplexy due to pure infarction have 
Fig. 3 Necrosis and T cell inflammation of pituitary. Anterior pituitary shows partial necrosis $(\mathbf{a}, \mathrm{HE} \times 40)$ with infiltration by numerous macrophages $(\mathbf{b}, \mathrm{KiM} 1 \mathrm{P} \times 40)$. Necrotic areas in the upper part are marked by arrows. T cell infiltrates with high numbers of cytotoxic $\mathrm{T}$ cells are found in the anterior pituitary $(\mathbf{c}$, CD3 $\times 40$, and $\mathbf{d}, \mathrm{CD} 8 \times 40)$ as well as posterior pituitary (e, CD3 $\times 40$ and $\mathbf{f}, \mathrm{CD} 8 \times 40$ ). Original magnification: a, $\mathbf{b} \times 10, \mathbf{c}-\mathbf{f} \times 20$. Scale bar $100 \mu \mathrm{m}$

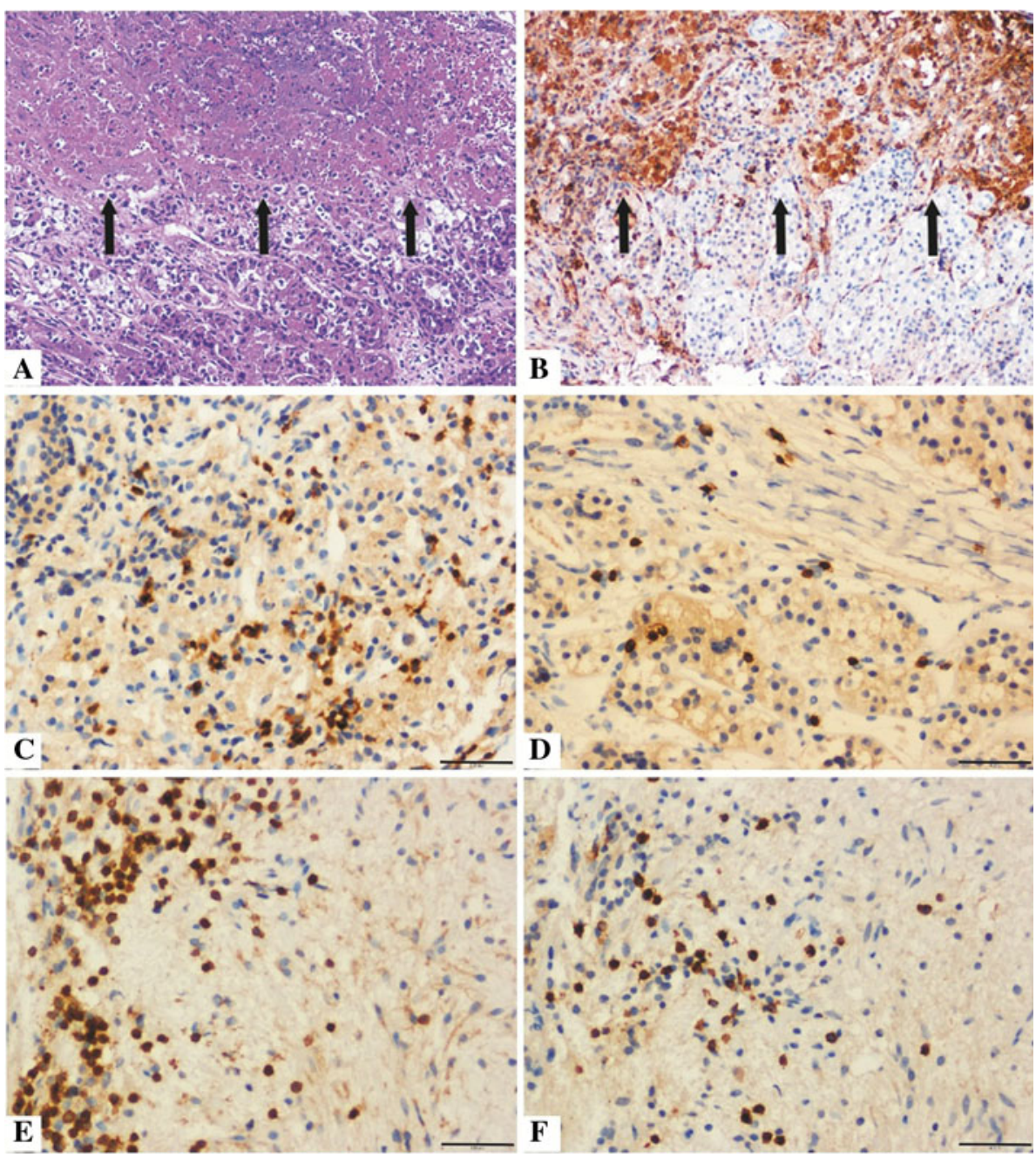

therefore been described [7, 15-18]. In cases with pituitary adenoma apoplexy, a peripheral rim enhancement is seen in those cases in which the interval between symptom onset and surgery constituted several weeks to months [18]. Pathologically, the enhancing rim corresponds to proliferating connective tissue, mononuclear cell infiltration, and atrophic endocrine cells at the edge of the infarction or hemorrhage. In general, however, pituitary necrosis is not accompanied by the marked lymphocytic infiltration seen in patients with infundibulo-neurohypophysitis, suggesting an autoimmune pathogenesis for this form.

Necrosis and apoptosis are tightly linked with autoimmunity. Apoptosis is a form of programmed cell death during which the cell order is dismantled, usually with fragmentation and release of apoptotic bodies. During this process the cytoplasmic membrane rearranges but remains intact so that no inflammatory reaction is elicited. The rearranged cell surface allows the binding of numerous factors such as the complement factor C1q [19] and the milk factor globule epidermal growth factor 8 [20] that suppress inflammation and promote the engulfment by macrophages and dendritic cells [21]. However, if the apoptotic cell is not removed promptly and efficiently, it progresses to a state of secondary necrosis in which the cytoplasmic membrane is eventually disrupted. The cell then becomes pro-inflammatory rather than immunosuppressive, capable of activating dendritic cells and lymphocytes [22]. In fact, failed removal of apoptotic cells is known to be associated with autoimmunity in both mice and humans [23]. The mechanisms through which an incompletely removed apoptotic cell favors initiation and propagation of an autoimmune response remain to be elucidated. Autoantigens may reach unusually high concentrations in apoptotic bodies or undergo post-translational modifications that make them better recognizable by the immune system. The pro-inflammatory environment can also lead to expression of class II MHC molecules on cells. In fact, pituitary cells are able to synthetize MHC class II molecules in experimental settings [24] as well as in patients with lymphocytic hypophysitis [1], which makes these cells ideally capable of interacting with activated immunocompetent cells. Moreover, experimental evidence 
suggests that not only neoplastic but also normal pituitary can support an inflammatory reaction via expression of multiple cytokines, including IL-1, IL-1 receptor agonist, IL-2, and IL-6 [25]. In pituitary necrosis, these cytokines may serve as an abnormal stimulant that elicits systemic or local inflammation, which can induce hypophysitis in the neighboring, residual normal gland. The small number of reported patients with necrotizing hypophysitis and the absence of an animal model specific for this pathological variant make it difficult to draw any conclusions.

Another possible scenario is the spontaneous development of pituitary necrosis that is without recognizable precipitating events as previously described [26]. Such a scenario seems unlikely in our young patient particularly since the necrosis was associated with lymphocytic infiltration of the remaining anterior and even posterior pituitary. We therefore think that the necrosis was secondary to the inflamed and enlarged pituitary gland, which is in keeping with the observation that the patient suffered from secondary hypogonadism for 3 years. After the gonadotropin insufficiency, our patient developed corticotropin, thyrotropin and growth hormone deficiency as well as diabetes insipidus. However, a spontaneous reduction in the size of her pituitary gland after surgical biopsy, along with a normal-appearing anterior pituitary and infundibulum, was demonstrated in consecutive MR control images. The posterior pituitary bright spot still did not reappear. Deficiency of the anterior and posterior pituitary function in our patient might be explained by ongoing autoimmune destruction of the gland. This autoimmune reaction is either primary, as would be the case in autoimmune hypophysitis preceding pituitary apoplexy, or secondary, as necrosis of the pituitary is known to initiate the liberation of autoantigens from the damaged cells, triggering secondary autoimmune process through pituitary autoantibodies [27]. The latter can not be proven in our case, as no pituitary antibodies were measured in our patient.

In conclusion, we report a young woman with diabetes insipidus and hypopituitarism, demonstrating a characteristic MRI appearance with symmetrical gland enlargement, loss of posterior pituitary bright spot, thickening and pathological enhancement of the pituitary stalk and infundibulum, as is usually seen in autoimmune hypophysitis [28]. Histopathology showed massive pituitary, nonhemorrhagic necrosis and lymphocytic infiltration of the normal-appearing anterior and posterior pituitary, as reported in two previously published cases of necrotizing infundibulo-hypophysitis [3]. The pathogenesis of this rare hypophysitis variant remains unknown.

Acknowledgments The work was supported in part by a Heidenreichvon-Siebold grant (Georg-August-University Göttingen) to AG. PC was supported in part by NIH grant DK 080351.
Open Access This article is distributed under the terms of the Creative Commons Attribution Noncommercial License which permits any noncommercial use, distribution, and reproduction in any medium, provided the original author(s) and source are credited.

\section{References}

1. Gutenberg A et al (2005) Immunopathology of primary hypophysitis: implications for pathogenesis. Am J Surg Pathol 29(3):329-338

2. Caturegli P et al (2005) Autoimmune hypophysitis. Endocr Rev 26(5):599-614

3. Ahmed SR et al (1993) Necrotizing infundibulo-hypophysitis: a unique syndrome of diabetes insipidus and hypopituitarism. J Clin Endocrinol Metab 76(6):1499-1504

4. Ogawa R (1995) A child with necrotizing infundibulo-hypophysitis. Hormone Rinsho 43:33-36

5. Gutenberg A, Landek-Salgado M, Tzou SC, Lupi I, Geis A, Kimura H, Caturegli P (2009) Autoimmune hypophysitis: expanding the differential diagnosis to CTLA-4 blockade. Expert Rev Endocrinol Metab 4(6):681-698

6. Reid RL, Quigley ME, Yen SS (1985) Pituitary apoplexy. A review. Arch Neurol 42(7):712-719

7. Semple PL et al (2006) Pituitary apoplexy: do histological features influence the clinical presentation and outcome? J Neurosurg 104(6): 931-937

8. Sheehan HL (1948) Post-partum necrosis of the anterior pituitary. Ir J Med Sci 19(270):241-255

9. Kovacs K (2003) Sheehan syndrome. Lancet 361(9356):520-522

10. Park $\mathrm{HJ}$ et al (2010) Antepartum pituitary necrosis occurring in pregnancy with uncontrolled gestational diabetes mellitus: a case report. J Korean Med Sci 25(5):794-797

11. Vergely $\mathrm{N}$ et al (1996) Acute pituitary necrosis after multiple pituitary stimulation test. Presse Med 25(37):1827-1829

12. Bria A et al (2000) Pituitary necrosis after spinal anesthesia: a case report. Ann Endocrinol (Paris) 61(2):164-167

13. Murthy GL et al (2002) Acute pituitary necrosis following snake envenomation. J Assoc Physicians India 50:452-453

14. Plaut A (1952) Pituitary necrosis in routine necropsies. Am J Pathol 28(5):883-899

15. Brougham M, Heusner AP, Adams RD (1950) Acute degenerative changes in adenomas of the pituitary body-with special reference to pituitary apoplexy. J Neurosurg 7(5):421-439

16. Mohr G, Hardy J (1982) Hemorrhage, necrosis, and apoplexy in pituitary adenomas. Surg Neurol 18(3):181-189

17. Bills DC et al (1993) A retrospective analysis of pituitary apoplexy. Neurosurgery 33(4):602-608; discussion 608-9

18. Kleinschmidt-DeMasters BK, Lillehei KO (1998) Pathological correlates of pituitary adenomas presenting with apoplexy. Hum Pathol 29(11):1255-1265

19. Botto $\mathrm{M}$ et al (1998) Homozygous C1q deficiency causes glomerulonephritis associated with multiple apoptotic bodies. Nat Genet 19(1):56-59

20. Hanayama R et al (2004) Autoimmune disease and impaired uptake of apoptotic cells in MFG-E8-deficient mice. Science 304(5674):1147-1150

21. Ravichandran KS, Lorenz U (2007) Engulfment of apoptotic cells: signals for a good meal. Nat Rev Immunol 7(12):964-974

22. Fransen JH et al (2009) Mouse dendritic cells matured by ingestion of apoptotic blebs induce $\mathrm{T}$ cells to produce interleukin17. Arthritis Rheum 60(8):2304-2313

23. Sheriff A et al. (2004) Apoptosis and systemic lupus erythematosus. Rheum Dis Clin North Am 30(3): 505-27, viii-ix 
24. Mauerhoff T, Miakian R, Bottazzo GF (1987) Autoimmunity and the pituitary. In: Doniach D, Bottazzo GF (eds) Endocrine and other organ-oriented autoimmune disorders. Bailliere's clinical immunology and allergy, vol 1, no 1, pp 217-235

25. Arzt E et al (1998) Cytokine expression and molecular mechanisms of their auto/paracrine regulation of anterior pituitary function and growth. Ann NY Acad Sci 840:525-531

26. Biousse V, Newman NJ, Oyesiku NM (2001) Precipitating factors in pituitary apoplexy. J Neurol Neurosurg Psychiatr 71(4): $542-545$
27. Goswami R et al (2002) Pituitary autoimmunity in patients with Sheehan's syndrome. J Clin Endocrinol Metab 87(9):4137-4141 28. Gutenberg A et al (2009) A radiologic score to distinguish autoimmune hypophysitis from nonsecreting pituitary adenoma preoperatively. AJNR Am J Neuroradiol 30(9):1766-1772 